\title{
COMUNICAÇÕES BREVES
}

BRIEF COMMUNICATIONS

Comunicaciones breves 


\title{
Axiodrama nas organizações
}

\author{
Axiodrama in organizations
}

\section{Axiodrama en las organizaciones}

\author{
Andréa Claudia de Souza*; Joceli Regina Drummond** \\ Potenciar Consultores Associados \\ e-mails: * andrea@potenciar.com.br ; **potenciar@potenciar.com.br
}

\begin{abstract}
Resumo
Este artigo aborda o método sociátrico e suas possibilidades de atuação. Trata-se de uma revisão bibliográfica com as diferenças e as semelhanças conceituais e contratuais entre Axiodrama, Psicodrama, Sociodrama e Teatro Espontâneo. Focaliza as práticas do Axiodrama no universo organizacional, exemplificado com um trabalho da área da saúde. Lidar com valores e ética mostra-se necessário, útil e eficiente no mundo atual, e deve-se estimular o processamento de diferentes axiodramas para ampliar essas discussões e referências.
\end{abstract}

Palavras-chave: teatro da espontaneidade, identidade organizacional, ética, psicodrama, axiodrama

\begin{abstract}
This article approaches the sociatric method and its possibilities of performance. It is a bibliographical review with conceptual and contractual differences and similarities among Axiodrama, Psychodrama, Sociodrama and Spontaneous Theater. It focuses on the Axiodrama practices in the organizational universe, exemplified by a work in the healthcare sector. Dealing with values and ethics is necessary, useful and efficient in today's world, and the processing of different axiodramas should be encouraged to increase these kind of discussions and references.
\end{abstract}

Keywords: theater of spontaneity, organizational identity, ethics, psychodrama, axiodrama

\section{Resumen}

Este artículo aborda el método sociátrico y sus posibilidades de actuación. Se trata de una revisión bibliográfica con las diferencias y las similitudes conceptuales y contractuales entre Axiodrama, Psicodrama, Sociodrama y Teatro Espontáneo. Foca en las prácticas del Axiodrama en el universo organizacional, ejemplificado con el trabajo de la area de la salud. 
Enfrentarse con valores y ética se muestra necesario, útil y eficiente en el mundo actual, y se debe estimular el procesamiento de diferentes axiodramas para ampliar esas discusiones y referencias.

Palabras clave: teatro de la espontaneidad, identidad organizacional, ética, psicodrama, axiodrama

\section{INTRODUÇÃO}

Jacob Levy Moreno, quando funda o Teatro da Espontaneidade, descobre a ação terapêutica da dramatização. Em sua obra, Moreno deixa explícita a sua compreensão do homem como ser social e, consequentemente, relacional, que se caracteriza pela espontaneidade e capacidade de perceber o outro (Lima \& Camossa, 2011).

Segundo Canel e Pelicioni (2007), com base na obra Psicodrama, de Moreno, "O psicodrama favorece a substituição de um sistema de valores já desgastado e obsoleto, que ele denomina de 'conserva cultural', por um outro que corresponda às necessidades atuais" (p. 433).

A substituição e a atualização dos valores têm como pilar a espontaneidade. A proposta do Psicodrama e do Axiodrama respeita a forma do fluir das relações. Não são abordadas questões morais, e sim éticas, de cunho grupal, capazes de valorizar e resguardar a sobrevivência psíquica de cada participante (Weill, 2002).

\section{O MÉTODO SOCIÁTRICO}

Entre os psicodramatistas existem discussões sobre a subdivisão dos métodos de tratamento da sociedade, ou, como chama Moreno, da Sociatria. Alguns psicodramatistas, como Moysés Aguiar (1998), consideram o Teatro Espontâneo como o verdadeiro método de trabalho da Sociatria, enquanto outros consideram mais o Psicodrama e o Sociodrama. Aqui usaremos estes dois como métodos, e suas variações podem ser vistas em dois exemplos: Axiodrama e Etnodrama, como mencionados por diversos autores.

Eis o dilema que precisa ser resolvido: ou tomamos Sociodrama como substantivo ..., criando "tipos" de Sociodrama, ou seguimos a classificação tradicional de Moreno, que destaca Axiodrama (campo axiológico-religioso), Etnodrama (síntese de etnologia e Psicodrama), do universo de significação de "Sociodrama". (Mezher, 2002)

\section{AXIODRAMA}

Encontramos algumas definições para Axiodrama, elegidas por diferentes psicodramatistas. Para Marineau (1992, p. 165), Axiodrama é uma "dramatização baseada na exploração de valores ético-sociais e elaborados por Moreno como uma maneira de desfazer-se das conservas culturais", portanto, a "finalidade última do Axiodrama é forçar cada um, ator, diretor, escritor e mesmo o expectador, a deixar aparecer sua verdadeira 'personalidade', ao invés de escondê-la sob uma máscara ou um papel'. E, antes mesmo de pensar e elaborar o Sociodrama e o Psicodrama, Moreno pensou no Axiodrama. 
Para Moreno (1974, p. 114), “o Axiodrama é uma síntese do Psicodrama e da ciência dos valores (axiologia); dramatiza as aspirações morais do psiquismo individual e coletivo (justiça, beleza, bondade, complexos, perfeição, eternidade, paz, etc.)". O "conteúdo" original do Psicodrama é axiológico.

Para Holmes, Karp e Watson (1998, p. 122), “o Axiodrama seria o teatro baseado na exploração de valores sociais éticos . . u um exorcismo da coercitividade social e um pretexto para um encontro real das pessoas sem suas máscaras". O que, nesse caso, seria não usar de conservas culturais para justificar pensamentos e ações.

Em Marra e Fleury (2008, p. 110), temos a origem da palavra Axiodrama baseada em "eixo" (áxon), portanto, em um tema ou assunto. Já na visão de Almeida (2012, p. 81), "axiologia" tem origem na palavra grega áksios (o que merece, o que vale) e "logia" (tratado, estudo, ciência); portanto, Axiologia é a ciência dos valores e dos merecimentos. Esses valores são móveis e dinâmicos, antagônicos e dialéticos e procuram ajudar o homem a entender o sentido da vida. $O$ autor cita alguns dos valores a serem trabalhados: valores utópicos; valores/desvalores; limites; virtuosos; da sensibilidade; da civilidade; valores/desvalores das relações humanas; valores/desvalores ligados ao desejo; políticos; e valores/desvalores religiosos (Almeida, 2012). Axiodrama é, então, para Almeida, a proposta moreniana para "trabalhar" dramaticamente os elementos da axiologia. Ele os divide em dois vértices: axiodrama e axiodrama tematizado. "Tematizado ou não, será sempre um Sociodrama, pois estará preocupado com o movimento sociogrupal" (Almeida, 2012, pp. 90-91). Faz questão de diferenciar Sociodrama de Axiodrama, considerando-os como paralelos e não derivados. Acredita que, apenas com a discussão das variáveis de um Axiodrama e sobre suas diferenças com relação aos sociodramas, o Axiodrama obterá sua justa nomeação, pois mesmo entre psicodramatistas de renome isto, muitas vezes, é pouco refletido. Também sugere o diálogo axiodramático (isso fora sugerido pela primeira vez por Vieira e Lofrano [citados por Almeida, 2012] em Congresso de Psicodrama de 1999) e os processamentos axiodramáticos.

Fonseca (2009) discute as diferenças entre Psicodrama, Sociodrama e Axiodrama públicos considerando o Psicodrama Público apresentado por Moreno a mais curta das psicoterapias.

A característica pública das sessões abertas permite plena apreensão dos valores socioculturais (contexto social) presentes. Esse fato transforma o Psicodrama ou Sociodrama público em um poderoso instrumento para o tratamento das síndromes culturais de uma sociedade. O objetivo é oferecer possibilidades para a comunidade se organizar diante de uma dificuldade, como no caso dos Sociodramas e dos Axiodramas que abordam epidemias, guerras, convulsões sociais etc. Constituem sociopsicoterapias in situ.

Rodrigues (2008) nomeia o Axiodrama como um dos procedimentos ou formato da sessão de um psicossociodrama, lembrando as novas nomenclaturas utilizadas no movimento psicodramático brasileiro como Sociopsicodrama e Psicossociodrama. Inclui na categoria procedimentos Psicodrama, Sociodrama, Sessão Aberta de Psicoterapia Psicodramática, Sociodrama Tematizado, Axiodrama e Comunidade em Cena.

Para Blatner (2008), o Axiodrama é mais abstrato e amplo que o Psicodrama e o Sociodrama, pois discute influências e valores e chega à visão mais global de determinados temas. A ruptura de determinadas influências e a maturidade de um grupo requerem grande esforço por parte de todos.

O Axiodrama reflete valores e crenças. O método consiste em dar corpo e voz a determinados valores e assumir os papéis destes, ajudando a ressignificá-los. Um movimento que leva do abstrato ou geral ao concreto ou específico, encontrando o que se tem de significativo. Axiodrama, nesse sentido, é uma forma de aplicação semântica "o que realmente se quer dizer com o uso desta ou daquela palavra?".

O Axiodrama explora a forma como uma rede social usa determinadas normas ou regras 
na vida pessoal de quem a integra, e o quanto estas podem ter sido determinadas pela sociedade, sem a total clareza de quem as reproduz. Por meio do Axiodrama, ficam expostas as condutas e as normas sociais de um grupo, que pode, então, ressignificar e rematrizar esses aprendizados.

Bezerra, Viana e Leonido (2013) lembram que, em termos de objetivos gerais, o Axiodrama alarga e vive a escolha dos valores, e pressupõe a partida de uma base teórica para a prática; do plano do discurso para o plano da ação. Esses autores defendem que "para vários autores é notória a ideia de valorização da imaginação, o lúdico, o riso, o humor, o amor e a alegria na ação de Moreno" (Bezerra, Viana, \& Leonido, 2013, p. 38), assim como o faz Ramalho (2011), que define o Axiodrama como método de transformação social que, por meio da experiência vivencial, desvela seus quadros de valores e promove mudanças nesses mesmos quadros (p. 76).

Dessa forma, optamos por defender o Axiodrama nas organizações como todo trabalho de abordagem e metodologia psico e sociodramática que vise refletir os valores e os desvalores de uma organização, ou grupo, partindo do princípio de que o próprio grupo pode se perceber, se avaliar e se reavaliar com a ajuda dos diretores, que cuidam para que se mantenham em campo axiológico mais relaxado e claro, dando luz ao que o próprio grupo protagonizar.

\section{PRÁTICA ORGANIZACIONAL}

Os trabalhos práticos desenvolvidos pela Potenciar e por seus consultores incluem diversos Axiodramas, isto é, trabalhos ou jogos dramáticos focados nos valores e nos desvalores de grupos e organizações.

Um modo de iniciar esse trabalho é o Mapeamento do Clima Organizacional, cujo objetivo é mostrar ao grupo seus próprios valores e suas crenças, e juntos rever missão, visão e valores grupais e organizacionais. Há momentos em que os trabalhos são preparados nesse sentido axiodramático e, conforme a demanda do grupo, alguns valores são especificamente focados, com o uso de fábulas, criação de brasões, lemas pessoais e outras técnicas. As etapas de desenvolvimento que constituem o Axiodrama são as mesmas do Sociodrama no contexto social. Também o Mapeamento do Clima descrito por Drummond e Souza (2008) segue com Aquecimento, Dramatização, Compartilhamento e Processamento.

De forma lúdica e já invertendo papéis, os participantes criam e dramatizam cenas do cotidiano, colocando-se nos grupos de gestores, clientes, terceiros, equipes, entre outros (conforme o enfoque do trabalho), para entenderem os valores que os regem e quais desvalores de um grupo são valores para outros, administrando os conflitos a partir da inversão de papéis e do entendimento do campo axiológico em que se encontram. Para exemplificar, citamos um trabalho desenvolvido em uma empresa da área da saúde, com equipe administrativa.

Público: Diferentes setores, como TI, recepção, atendimento de balcão, atendimento telefônico, financeiro.

Objetivo da empresa: Treinamento para o atendimento humanizado.

Objetivo da atividade do Axiodrama: Refletir os valores individuais e grupais que permeiam o atendimento humanizado.

Esse trabalho resgatou os valores principais da empresa, em confronto com os valores pessoais e os conflitos gerados entre os valores e a missão definidos no papel (documento da empresa) e os vivenciados pelo grupo em seus setores. 
Após o aquecimento adequado no campo organizacional (não é preciso necessariamente um aquecimento tão corporal, mas a criação de um clima criativo e espontâneo), subdividimos os grupos e pedimos que criassem cenas que demonstrassem situações de conflitos de valores.

Cena 1: $\mathrm{O}$ atendimento de uma idosa acompanhada da filha, sem a carteirinha do convênio.

Cena 2: O encaminhamento de um paciente para a realização do exame de espermograma.

Cena 3: Pedido de ambulância para deslocamento de paciente, por parte da enfermagem, sem abertura de chamado em Tecnologia da Informação. Urgência versus Procedimentos.

Por meio das técnicas de duplo, espelho, solilóquio, maximização, inversão de papéis, as cenas foram trabalhadas, desvelando diferentes modos de pensar e valores individuais.

O conflito representado e discutido é a missão da empresa, que envolve o atendimento humanizado aos clientes; no entanto, os valores pessoais do grupo se dividem em relação ao que cada grupo considera atendimento humanizado. Enquanto para um, o atendimento humanizado deve ser afetivo e com atenção a todas as demandas, para outro, o atendimento humanizado deve ser rápido, eficaz e eficiente, de acordo com o serviço proposto. Por exemplo, para um grupo seria a agilidade no preenchimento de fichas e nos encaminhamentos, enquanto para outro seria o conforto no atendimento, funcionários atenciosos e prestativos. Deparandose com as diferenças, porém respeitando-as, o grupo chegou à conclusão de que o processo de humanização pode ter vários caminhos, mas a humanização no atendimento deve ser o valor central. Ao final, ampliaram a visão do que fazer e como fazer no atendimento aos pacientes.

\section{O AXIODRAMA EM OUTROS CONTEXTOS}

Nosso segundo exemplo é um trabalho realizado em escolas, onde o tema mais comum tem sido os valores da educação e da família, e qual o papel da família do estudante para os professores.

Um terceiro exemplo de trabalho é o realizado em uma empresa varejista cujos valores dos vendedores variavam entre o ganho da comissão a qualquer custo e os cuidados com o revezamento entre os colegas para que todos lucrem. O valor amizade foi o mais discutido dentro desse ambiente organizacional.

Os diálogos axiodramáticos, os processamentos axiodramáticos e, por fim, os Axiodramas nas organizações, independentemente de seus propósitos, possibilitam que venham a ser mais saudáveis e promotoras de saúde.

\section{CONCLUSÃO}

Muito ainda há para se dizer de Axiodrama por psicodramatistas do foco psicoterápico ou socioeducacional e, em especial, no campo organizacional. Encontramos muitos trabalhos já realizados, e a estimulação de novos protocolos que discutam essas temáticas pode ser um desafio a professores e supervisores de Psicodrama.

Conforme vemos em Mezher (2002), a ética no Psicodrama acompanha o próprio grupo e é coconstruída, mas os psicodramatistas precisam ter plena consciência do campo axiológico em que se encontram. 
Antes de discutirmos valores de outras pessoas, precisamos discutir e repensar os nossos próprios valores. Defendemos a ideia de que o Axiodrama permaneça dentro do método do Sociodrama, mas com foco específico para os valores do grupo.

\section{REFERÊNCIAS}

Aguiar, M. (1998). Teatro espontâneo e psicodrama. São Paulo: Ágora.

Almeida, W. C. (2012). Rodapés psicodramáticos. Subsídios para ampliar a leitura de J. L. Moreno. São Paulo: Ágora.

Bezerra, S. Q., Viana, R. S., \& Leonido, L. (2013). Teatro espontâneo: Um instrumento de sensibilização para os (futuros) administradores. European Review of Artistic Studies, 4(2), 2844. Recuperado em 12 de julho de 2016 de http://www.eras.utad.pt/docs/JUN\%202013\%20estudos\%20teatrais1.pdf

Blatner, A. (2008). Axiodrama. Recuperado em 12 de julho de 2016 de http://www.blatner.com/adam/pdntbk/Axiodrama.html

Canel, R. C., \& Pelicioni, M. C. F. (2007, julho-setembro). Psicodrama pedagógico: Uma técnica participativa para estratégias de promoção de saúde. Mundo Saúde, 31(3), 426-433. Recuperado em 19 de novembro de 2014 de http://pesquisa.bvsalud.org/bvsms/resource/pt/mis17130

Drummond, J., \& Souza, A. C. (2008). Sociodrama nas organizações. São Paulo: Ágora.

Fonseca, J. (2009). Psicodrama, sociodrama e axiodrama público. Recuperado em 17 de agosto de 2016 de http://www.psicorama.com.br/artigo_detalhe.asp?ID=74\&COLID=43

Holmes, P., Karp, M., \& Watson, M. (1998). O psicodrama após Moreno. São Paulo: Ágora.

Lima, N. S. T., \& Camossa, D. A. (2011). O psicodrama e sua contribuição para a saúde mental. Revista de Ciências da Educação, 25, 319-332. Recuperado em 19 de novembro de 2014 de http://www.revista.unisal.br/ojs/index.php/educacao/article/viewFile/105/170

Marra, M. M., \& Fleury, H. J. (2008). Grupos - Intervenção socioeducativa e método sociodramático. São Paulo: Ágora.

Marineau, R. F. (1992). Jacob Levy Moreno: 1889-1974. São Paulo: Ágora.

Mezher, A. (2002). A ética nos grupos: Contribuição do psicodrama. São Paulo: Ágora.

Moreno, J. L. (1974). Psicoterapia de grupo e psicodrama (A. C. M. Cesarino Filho, Trad.). São Paulo: Mestre Jou.

Ramalho, C. M. R. (2011). Psicodrama e dinâmica de grupo. São Paulo: Iglu.

Rodrigues, R. (2008). Quadros de referências para intervenções grupais psico-sociodramáticas. Revista Brasileira de Psicodrama, 16(1), 75-92.

Revista Brasileira de Psicodrama, v. 25, n. 1, 87-93, 2017 
Weill, P. (2002). A ética nos grupos: Contribuição do psicodrama (Prefácio). São Paulo: Ágora.

Recebido: 23/08/2016

Aceito: 20/04/2017

Andréa Claudia de Souza. Professora Doutora em Psicologia Clínica pela Universidade Autónoma de Lisboa (UAL). Mestre em Psicologia da Saúde pela Universidade Metodista de São Paulo (UMESP). Psicóloga pela Universidade Metodista de São Paulo (UMESP). Psicodramatista Didata Supervisora pela Potenciar Consultores Associados. Avenida Wallace Simonsen, 1127, Nova Petrópolis, CEP 09771-211. São Bernardo do Campo, SP. Tel.: (11) 99932-8747.

Joceli Regina Drummond. Professora Doutora em Psicologia Clínica pela Universidade Autónoma de Lisboa (UAL). Mestre Multidisciplinar em Educação e Administração de Empresa pela Universidade São Marcos (USM). Direct Group no Institute Moreno de Beacon (IMB), EUA. Psicodramatista Didata Supervisora pela Potenciar Consultores Associados. Rua Dr. José Maria Whitaker, 311, Morumbi, CEP 05621-001. São Paulo, SP. Tel.: (11) 992500866. 